\title{
An Agent-based dynamic occupancy schedule model for prediction of HVAC energy demand in an airport terminal building
}

\author{
Kapil Sinha ${ }^{1}$, Nusrat Ali $^{1}$, E. Rajasekar ${ }^{1}$ \\ ${ }^{1}$ Indian Institute of Technology Roorkee, Roorkee, India
}

\begin{abstract}
Airport terminal buildings are characterised by rapidly fluctuating occupancy levels in different zones. Occupancy is one of the major factors that influences the indoor environment and building energy consumption. The paper presents an approach to couple pedestrian flow model with energy simulation to predict the HVAC energy demands in the transitional environments. For the study, a medium sized airport at Visakhapatnam, India, located in warm and humid climate zone is considered. Occupancy dynamics of the terminal building is modelled and analysed through an agent based model (ABM). The results show a significant difference in the characteristics of the occupancy profiles between the various zones in the terminal building. A coupled energy simulation is carried out using the dynamic occupancy schedule obtained from $\mathrm{ABM}$. The paper presents the impact of pedestrian density on HVAC loads at different zones. Also load profile for typical days compared for the peak load performance. Finally, the paper presents the comparison of HVAC loads predicted using the occupancy schedule based on flight operations and dynamic occupancy schedule based on agent based simulations.
\end{abstract}

\section{Introduction}

The civil aviation industry in India has emerged as one of the fastest growing industries in the country in the recent years. India is expected to become the third largest air passenger market by 2024 (IATA, 2018). Government is targeting five-fold increase in capacity at 124 airports. Terminal buildings are very energy intensive infrastructure and one of the highest energy consuming buildings (B. Edwards, 2005). The energy consumption in a major airport terminal lies between 100-300 GWh/Year which is comparable to 30,000 to 100,000 households(CASCADE Consortium, 2012). Since a uniform thermal environment is to be maintained throughout the large volumes of spaces, an energy intensive HVAC solution is required. These system contributes a large share of energy consumption in terminal buildings which is about 66\% in Ahmedabad Terminal and $80 \%$ in Adnan Menderes Terminal(Alba \& Manana, 2016). Unlike office and residential buildings, terminal buildings have rapidly fluctuating occupancy levels throughout the different zones like check-in, security Check, hold rooms. Hence passenger occupancy plays a vital role in determining HVAC energy demand. Previous study by Mambo, Eftekhari, Steffen, \& Ahmad,
2015 on occupancy based HVAC systems in terminal buildings concludes that $21-48 \%$ of the total energy could be reduced by occupancy flow based controllers.

There have been few studies on impact of occupancy in energy consumption in recent years. Study on Occupancy diversity on HVAC energy efficiency conducted by Yang et al., 2016 suggests that occupancy diversity results in increase of loads that are not actual demand for HVAC system, leading into inefficiency. Liu et al., 2018 concluded that heat gain from the occupants is a significant contributor of total internal gain in a terminal building. Heat generated by occupants was measured to $108 \mathrm{GJ}$ compared to $205 \mathrm{GJ}$ for lighting heat gain.

Occupancy prediction is one of the major challenge in the estimation of peak demand and total energy consumption. There has been studies like (Liu, Liu, et al., 2018) and (Liu, Li, et al., 2018) in which dwell time for every zone collected using a questionnaire based survey while the number of passengers were calculated using surveillance video. There has been wide range of studies conducted to predict the occupancy for energy prediction in recent times. The paper by Yu, Fung et al., 2011 presents a cluster analysis approach to study the occupant behaviour. Studies conducted by Virote et al., 2012; He et al., 2015; Tahmasebi et al., 2016; presents stochastic methods for the occupancy modelling. Chen et al., 2018 have developed an agent based stochastic occupancy simulator to stimulate presence and movement of each occupant by using three stochastic models. This model was used to generate sub-hourly occupant schedules for individual spaces of a small office building.

Agent based simulation models have emerged as a significant aid for predicting the impact of service time in pedestrian oriented activities. The study conducted by Verma et al., 2018 at Bangalore airport presents the use of agent based simulation for the prediction of dwell timings with the service time as input at various stages of services.

The objectives of the study are to: (a) Evaluate the dynamics of passenger occupancy at different zones in terminal building during arrival and departure sequences (b) Estimate the HVAC energy demand using the dynamic occupancy profiles obtain through ABM (c) Compare the HVAC load and estimate energy use obtained using the occupancy schedule based on flight operations and dynamic occupancy schedule based on agent based simulations. 


\section{Details of the study}

A medium sized airport at Visakhapatnam $\left(17.68^{\circ} \mathrm{N}\right.$, $83.21^{\circ} \mathrm{E}$ ), India is considered in the study. The terminal building has experienced significant passenger growth in the last decade with the construction of a new terminal. There is a significant growth in International passengers of about $36 \%$ in the last year. The airport handled about 2.5 million passengers in 2017-18 with nearly 65 aircrafts movement per day. The Airport consist of single terminal building for serving both domestic and international passengers. Airport experiences a morning peak (6AM8AM) and evening peak (6PM-7PM) of passengers travelling in domestic flights. The terminal building is situated about $7 \mathrm{~km}$ away from city and about $8 \mathrm{~km}$ from the Bay of Bengal coast. Visakhapatnam represents a warm and humid climate zone as per national building code of India. It is classified as Climate zone $1 \mathrm{~A}$ as per ASHRAE 169-2006 which refers to a very hot and humid climate.The city experiences all the three major seasons of summer, monsoon and winter. The hottest month are May and June in which maximum temperature frequently goes beyond $35^{\circ} \mathrm{C}$.

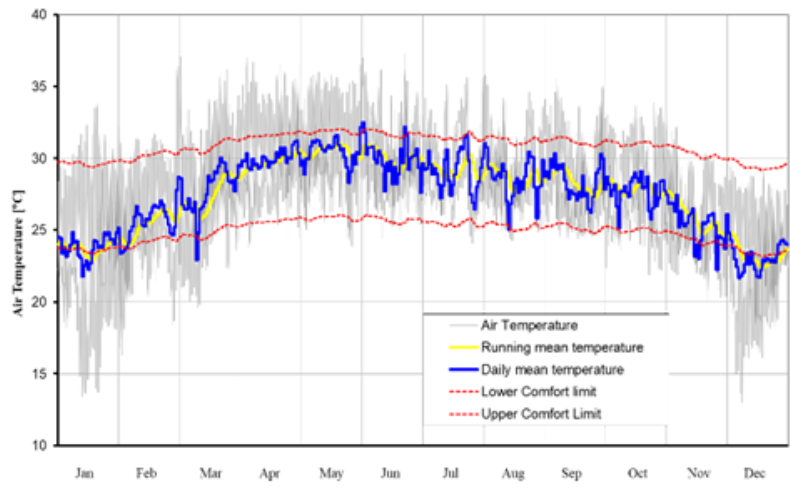

Figure 1 Annual variation in air temperature (running mean /daily mean) for Visakhapatnam; Source : ISHRAE TMY2 data

\section{Building Description}

The terminal building is operational since 2009 and features a glass and steel construction. It has a floor area of $20400 \mathrm{~m}^{2}$ and is designed to hold 300 arrival passengers and 700 departing passengers. The terminal building has two floors available for passenger movement. Majority of the passenger flow is confined to the ground floor which consist of visitor concourse, passenger concourse, check-in hall, security checks, immigration checks, hold-rooms (1 international and 1 domestic), baggage carousel and arrival hall. The first floor has hold-rooms along with airside corridor equipped with three aerobridges.

Check-in hall with a height of $14 \mathrm{~m}$. is the largest zone in the terminal building (volume: $18300 \mathrm{~m}^{3}$. Check-in hall is connected to passenger concourse, security checks and baggage separated through interior glass partition $(2 \mathrm{~m}$. height). The study categorizes the terminal building into 16 zones based on the characteristics of passengers which includes dwelling time, occupant density and activity level.

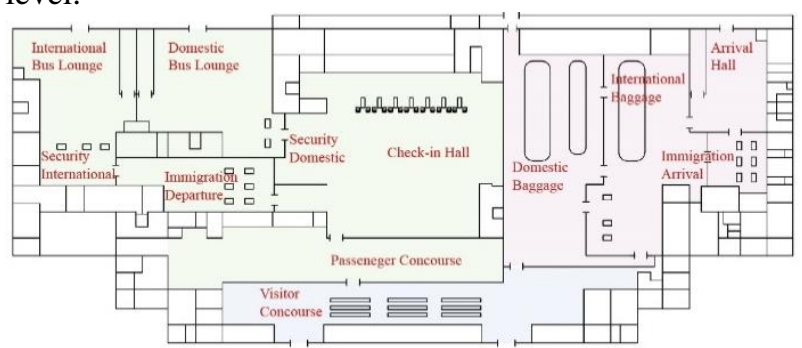

Figure 2: Layout plan of the terminal building (Ground floor)

\section{Methodology}

The paper presents an approach to couple pedestrian flow model with energy simulation to estimate the HVAC energy demands in the terminal building. The study is categorised into two modules: pedestrian flow simulation and energy simulation. Occupancy dynamics of the terminal building is modelled and analysed through an agent based simulation tool (AnyLogic) followed by energy simulation carried out using the dynamic occupancy schedule.

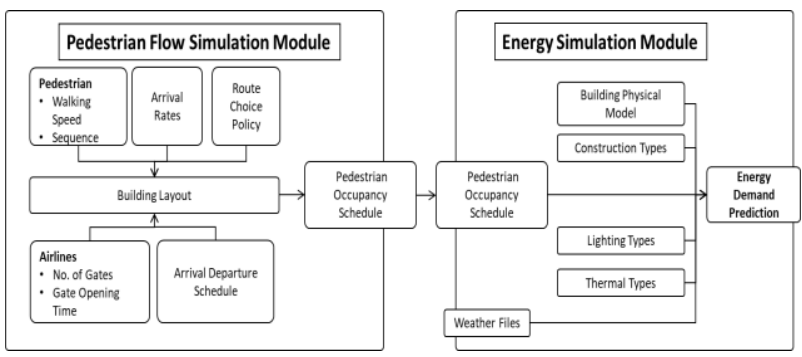

Figure 3: Integration between pedestrian flow model and energy simulation model

\section{Passenger flow modelling}

Passenger flow model is a sequence of events performed by the passengers during arrival and departure process. For this study, these set of events are categorized into process event and choice event based on the type. Process event is denoted by $\mathrm{P}$ and choice event is denoted by $\mathrm{C}(\mathrm{n})$ where $\mathrm{n}$ is number of choices offered. The nomenclature used in describing the passenger flow process is defined in Table 1. Arrival and departure process in the terminal building is explained in further section.

Table 1: List of choice events performed by the passenger agent

\begin{tabular}{|l|c|l|}
\hline Choice Event & Abbr. & Options \\
\hline Curb-side & $C_{\text {curb }}$ & wait/serve \\
\hline Visitor Concourse & $C_{\text {type }}$ & Visitor/passenger \\
\hline $\begin{array}{l}\text { Passenger } \\
\text { concourse }\end{array}$ & $C_{\text {conc }}$ & Restaurant/washroom/wait \\
\hline $\begin{array}{l}\text { Check-in type } \\
\text { assignment }\end{array}$ & $C_{\text {mode }}$ & Online/counter/baggage \\
\hline $\begin{array}{l}\text { Check-in counter } \\
\text { assignment }\end{array}$ & $C_{\text {count }}$ & Airline counters \\
\hline $\begin{array}{l}\text { Travel Type } \\
\text { Boarding floor } \\
\text { assignment }\end{array}$ & $C_{\text {fravel }}$ & Domestic/International \\
\hline
\end{tabular}




\section{Departure process}

When a passenger agent reaches the airport terminal curbside. The curb-side of the terminal building is choice event which offers two choices to the passenger i.e. $C_{\text {curb }}$ (wait) for wait and then access the service whereas $C_{\text {curb }}$ (serve) for the passengers to directly access the service.

Once a passenger agent decides to enter the terminal building, agent has to go through a ticket checking process $\left(P_{\text {ticket }}\right)$, where passenger's ticket is checked and identity is verified by the security personnel. Once process $P_{\text {ticket }}$ is completed, agent has to perform two process events $\left(P_{\text {checkin }}\right.$ and $\left.P_{\text {dom.security }}\right)$ in case of $C_{\text {travel }}$ (domestic) route. If the agent chooses the $C_{\text {travel }}$ (international) route, it is followed by three process $P_{\text {checkin }}, P_{\text {dep.imm }}$ and $P_{\text {int.security }}$ to complete the departure process. While performing the departure process, agent has to pass through five choice events, namely $C_{\text {type }}, C_{\text {mode }}, C_{\text {count }}, C_{\text {travel }}$ and $C_{\text {floor }}$. Visitor concourse $\left(C_{\text {type }}\right)$ is the choice event to filter the visitor and passenger agents. Only agents who choose the $C_{\text {type }}$ (passenger) is allowed to perform further events. Passenger concourse $C_{\text {conc }}$ is associated with discretionary event such as restaurant (rest), washroom $C_{\text {conc }}$ (wash) and waiting $C_{\text {conc }}$ (wait).

Check-in Hall consist of three choice events. $C_{\text {mode }}$ distinguishes the stream of passenger agents into different categories of check-in mode such as online and counter based check-in. Agent choosing $C_{\text {mode }}$ (online) is directly assigned to choice process $C_{\text {travel }}$ which determines security checks. There are 20 check-in counters in the check-in zone. These check-in counters are allotted to agent as per choice event $C_{\text {count }}$, based on the flight number. $C_{\text {travel }}$ event determines whether the passenger is domestic or international. Domestic security checks have 4 counters while international security have 3 counters. The security counters are assigned based on the queuing length. After the completion of check-in and security check, passenger agents are directed towards the $C_{\text {floor }}$ process which directs the passenger to go to their respective hold rooms either at ground floor or at first floor. There are two hold-rooms in ground floor and first floor. There are 1 International and 1 domestic hold room on each floor. The allocation of hold-room depends on the flight number. For the passengers boarding their flight via aerobridge, go through escalator or elevator to reach first floor. While the other passenger agents have to wait on the ground floor hold rooms for their flight. Passenger has to wait in hold-rooms till the boarding process starts.

\section{Arrival process}

While performing arrival sequence, passenger agent is required to perform different set of events based on travel type (International or Domestic). In case of domestic passenger, Agent is required to perform one choice event $C_{\text {baggage }}$ and one process event $P_{\text {baggage }}$. There are two baggage belt for the domestic passengers. $C_{\text {baggage }}$ assigns the baggage belt number to the agent based flight number. In case of international passenger, agent is required to perform three process events and one choice event. Three process events are arrival immigration $\left(P_{\text {arr.imm }}\right)$, Baggage Carousel $\left(P_{\text {baggage }}\right)$ and Custom check $\left(P_{\text {custom }}\right)$. The terminal building has four arrival gates, 3 gates are in the first floor which connected via aerobridge, while 1 is at the ground floor for the passengers arriving through bus. Terminal has two arrivals each at ground floor and first floor. After arrival passenger walk through the airside corridors to reach the arrival hall. Passengers arriving at first floor has to come to the ground floor for their baggage via escalator and elevator. The allocation of the baggage carousel is based on the flight demand. Terminal building has two separate baggage zone for international and domestic passengers. The domestic zone has 2 carousels while the international zone has 1 carousel. In arrival hall, stream of passengers is divided into international and domestic passengers. International passengers have to pass through the queuing system at immigration counter before baggage carousel. In the baggage carousel zone passenger stream is again divided into two categories depending upon the passengers with baggage and without baggage. Once the baggage collection activity is performed, domestic passengers directly move towards the exit gate, while the international passengers has to pass through custom checks.

\section{Field investigation}

The passenger flow in the airport terminal is service oriented sequence and hence service points are identified in the terminal building based on the departure and arrival process described in previous sections. There were eight service points identified in the process of arrival and departure. A pilot study is conducted to obtain the input for the modelling of choice process and stochastic process. Firstly, for the departure process, measurement is taken at the service point at departure entry gate, checkin counters, security checks and immigration counters. Similar to the departure process, service points are identified for the arrival process and measurement is obtained. Measurement is carried out in all the service points and processing time of the service is measured as follows:

$$
T_{\text {checkin }}=\tau_{\text {start }}-\tau_{\text {end }}
$$

Where $T_{\text {counter }}$ is processing time at the service counter; $\tau_{\text {start }}$ is the time at which passenger reaches the service counter and $\tau_{\text {end }}$ is the time at which passenger leave the counter after servicing is completed. Table 2 presents the probability distribution with parameter observed during the field investigation. The probability distribution is used for modelling the stochastic process at various service at airside corridor in the unobstructed stretch of $40 \mathrm{~m}$. The average walking speed obtained is $0.7 \mathrm{~m} / \mathrm{s}$ with a standard deviation of $0.37 \mathrm{~m} / \mathrm{s}$. 


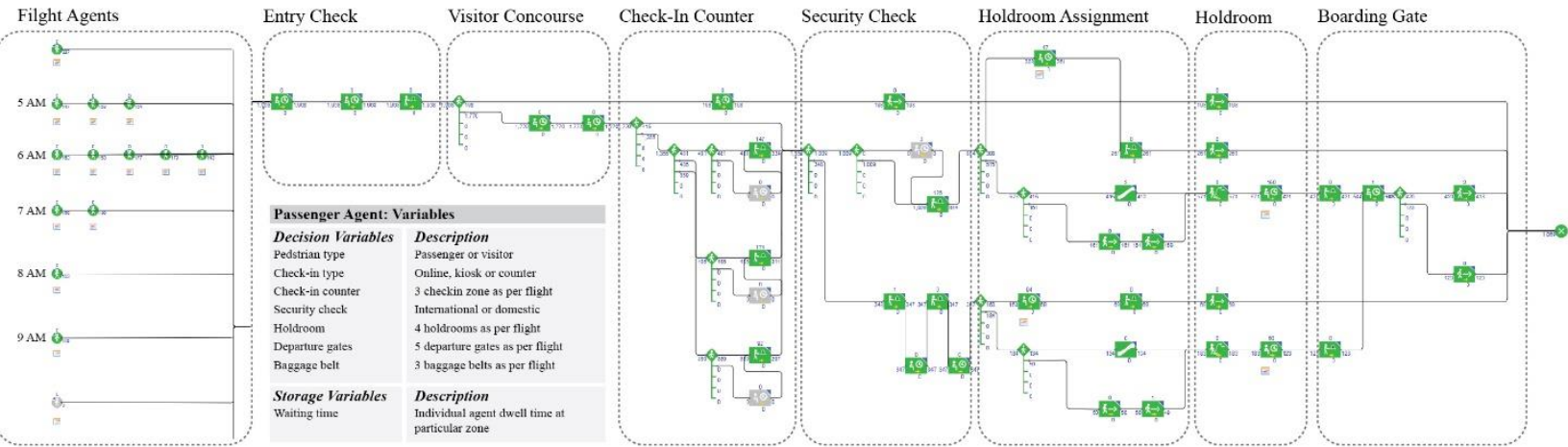

Figure 4: Series of discrete events performed by the agent in the process of departure in the terminal building modelled in AnyLogic

\section{Agent based modelling}

Agent based model of passenger flow for the terminal building is developed using AnyLogic software tool. The software provides a graphical interface for modelling the complex stochastic environment. For this study, the entire operation at the terminal are categorised into separate discrete events shown in Figure 4. And between these events, the passenger agents are modelled as per the characteristics of the passengers observed during the field investigation. Modelling of the discrete events and agent is described in the next section.

Table 2 : Probability distribution of processing time and number of counter of various service points

\begin{tabular}{|l|l|l|l|}
\hline Service Points & $\begin{array}{l}\text { No. of } \\
\text { Counter }\end{array}$ & $\begin{array}{l}\text { Probability } \\
\text { Distribution }\end{array}$ & $\begin{array}{l}\text { Parameter } \\
\text { (in } \\
\text { minutes) }\end{array}$ \\
\hline $\begin{array}{l}\text { Departure Entry } \\
\text { Gates }\end{array}$ & 3 & Uniform & $\begin{array}{l}\mathrm{a}=0.25, \\
\mathrm{~b}=0.52\end{array}$ \\
\hline $\begin{array}{l}\text { Check-in } \\
\text { Counters }\end{array}$ & 20 & Normal & $\begin{array}{l}\mu=3.8, \\
\sigma=0.36\end{array}$ \\
\hline $\begin{array}{l}\text { Domestic } \\
\text { Security Checks }\end{array}$ & 4 & Normal & $\begin{array}{l}\mu=2.8, \sigma \\
=1.4\end{array}$ \\
\hline $\begin{array}{l}\text { Departure } \\
\text { Immigration }\end{array}$ & 6 & Normal & $\begin{array}{l}\mu=2.1, \\
\sigma=0.25\end{array}$ \\
\hline $\begin{array}{l}\text { International } \\
\text { Security Checks }\end{array}$ & 3 & Normal & $\mu=3, \sigma=1.5$ \\
\hline $\begin{array}{l}\text { Arrival } \\
\text { Immigration }\end{array}$ & 5 & Normal & $\mu=3, \sigma=1.1$ \\
\hline $\begin{array}{l}\text { Customs } \\
\text { Counter }\end{array}$ & 4 & Normal & $\begin{array}{l}\mu=1.5, \\
\sigma=1.2\end{array}$ \\
\hline $\begin{array}{l}\text { Baggage } \\
\text { carousel }\end{array}$ & 3 & Normal & $\begin{array}{l}\mu=8.4, \\
\sigma=2.3\end{array}$ \\
\hline
\end{tabular}

The different discrete events during the process of arrival and departure is classified into two sub categories based on their function. Service points are modelled as stochastic process based on the data collected during the field investigation. While the decision making events during the sequence follows choice model. These individual discrete events are then sequenced as per the arrival and the departure process explained in the previous sections. Figure 5 explains the choice model and stochastic process for departure process in the terminal building. The bold label represents the stochastic process while the diamond shape represents the choice model.

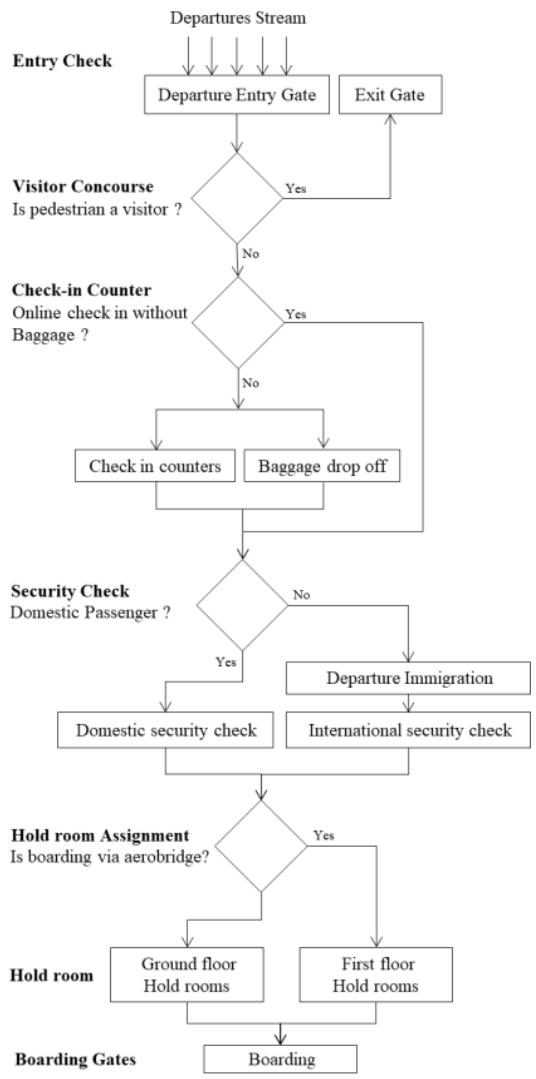

Figure 5 : General departure process performed by passengers

Some of the stochastic process such as check-in and security involves queuing of the passengers. The process involves queue modelling apart from the stochastic service models. Check-in process is modelled as single serpentine queuing with 5 service points. The service team is sensitive towards the servable length of the queue. To model this behaviour two subgroups are created, based on length of queue viz. high crowded and low crowded. In case of check-in, queuing area can hold up to 350 passengers at a time. On the basis of this 150 passengers 
are categorised as low crowded. During the process when there is low crowd, only 3 check-in counters are functional while when there is high crowd all the 5 counters are functional.

Agent based approach is used to take account of the individual passenger's transition in the terminal building. Hence every passenger is modelled separately using AnyLogic. Walking speed of all the passenger agents are randomly assigned using normal distribution $(\mu=0.7$, $\sigma=0.37 \mathrm{~m} / \mathrm{s}$ ). Point of service for the passenger depends upon the factor such that the mode of check-in. In order to determine the service points for the passengers, each passenger agent is assigned characteristics to take decision while performing the sequence. For the modelling of the passenger characteristics, agent with decision variable and storage variable is developed as described in the Figure 4. The passenger agents are then grouped according to their flight agents. The flight agent is then triggered using the function which follows the departure and arrival schedules provided by the airport authority.

\section{Energy Modelling}

Building energy model for the terminal building is developed using OpenStudio software tool and energy simulation is performed using EnergyPlus engine. The following section explains the modelling procedure in detail.

The terminal building is categorised in 68 thermal zones based on spatial characteristics. These thermal zones are further categorised into 19 space types based on the internal loads and operational schedules. Since terminal building consist of many large volumes and connected spaces, these spaces are further divided into subzones by creating thermal space boundary for a holistic output.

Construction material is assigned to the corresponding geometry as per the specification provided in the as built drawing. Lighting and occupant heat gain are the major contributors of total internal gains in the terminal building (Liu, Liu, et al., 2018). Each zone in the terminal building is associated with different level of activities and have their corresponding metabolic rates. Therefore, the space is categorized in three classes based on the activity levels viz.; walking, standing and sitting. The occupant load for the zone with the major activity as walking is taken as 285 $\mathrm{W} /$ person. While zones with standing and sitting activity are taken as $133 \mathrm{~W} /$ person and $115 \mathrm{~W} /$ person. Lighting load is assumed as $16.14 \mathrm{~W} / \mathrm{m}^{2}$ for the service area such as check-in counter and security check. The lighting load of $6.45 \mathrm{~W} / \mathrm{m}^{2}$ is taken for the concourse and $10.76 \mathrm{~W} / \mathrm{m}^{2}$ for the baggage areas as per ASHRAE 90.1-2007. The infiltration rate of 0.61 ach (Liu, Liu, et al., 2018) is taken considering opening and closing of gates.

\section{Simulations with dynamic occupancy schedules}

The study focus on the impact of occupancy schedule on the energy implication of the terminal buildings and the occupancy prediction model is developed using ABM. Passenger occupancy at different zones of the terminal is predicted for a typical operational day at an interval of 1 minute. Results from the ABM simulation is then converted to EnergyPlus schedule using small processing script. The zone wise occupancy schedule is then used as an input for the energy simulation. For the prediction of HVAC loads, ideal air loads are considered for all zones accessible to the passengers maintained at $24^{\circ} \mathrm{C}$. The HVAC loads for the terminal building is predicted for a typical summer day (May 21) at an interval of 1 minute. Also an annual simulation at a reporting interval of 10 min. is performed to predict the annual cooling load.

\section{Results}

Firstly, the occupant count at the different zone of the terminal building is predicted through the ABM simulation for typical operational day. Occupancy fluctuation at different zones of terminal building is shown in Figure 6. The occupancy fluctuation in check-in zone shows larger variation with a mean occupant count of 150 and standard deviation of 136 . The peak occupancy in check-in zone is obtained to be 425 passengers during the morning peak. The maximum occupancy throughout the zone is observed in domestic hold room with occupant count of 496. The overall peak occupancy of 1378 is

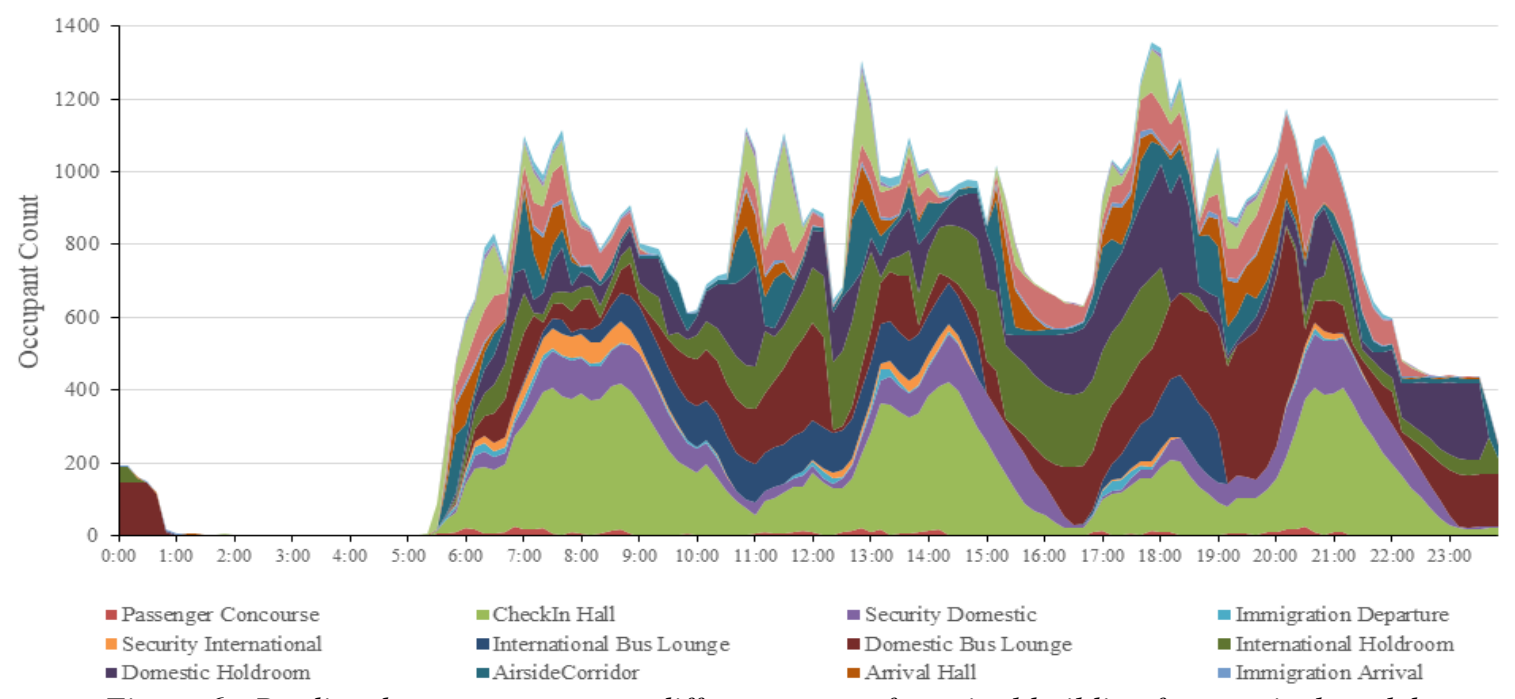

Figure 6 : Predicted occupant count at different zones of terminal building for a typical weekday 
observed in the terminal building during the evening peak hours. Occupancy profile of all the zones are obtained from the simulation results. Comparing the occupancy profile of various zones, it was observed that all holdrooms show different characteristics from the other zones in the terminal. A comparison of occupancy profile of check-in and hold-room is shown in Figure 7. The holdroom occupancy profile shows gradual increase in the occupant count till the peak is achieved and there is sudden drop in the occupant count as soon as boarding starts. While other zones such as check-in shows a gradual increase in the occupant count till the peak then there is gradual decrease.

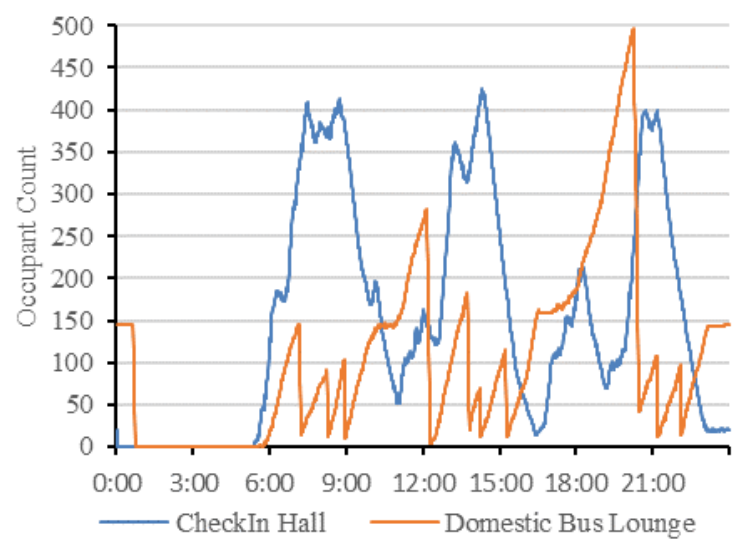

Figure 7 : Comparison of occupancy profiles in Checkin hall and Hold room during an operational day

Secondly, passenger dwelling time at the different zone of the terminal building is predicted through the ABM simulation for typical operational day. The mean dwelling time of $36 \mathrm{~min}$. is obtained at international hold-room which is highest amongst the zones in the terminal building while lowest mean dwelling time is observed in immigration arrival zone which is less than $4 \mathrm{~min}$. The mean dwelling time of $11 \mathrm{~min}$. is obtained in check-in zone while $13 \mathrm{~min}$. is obtained for security checks. Figure 8 shows the dwelling time at the different zone of the terminal building.

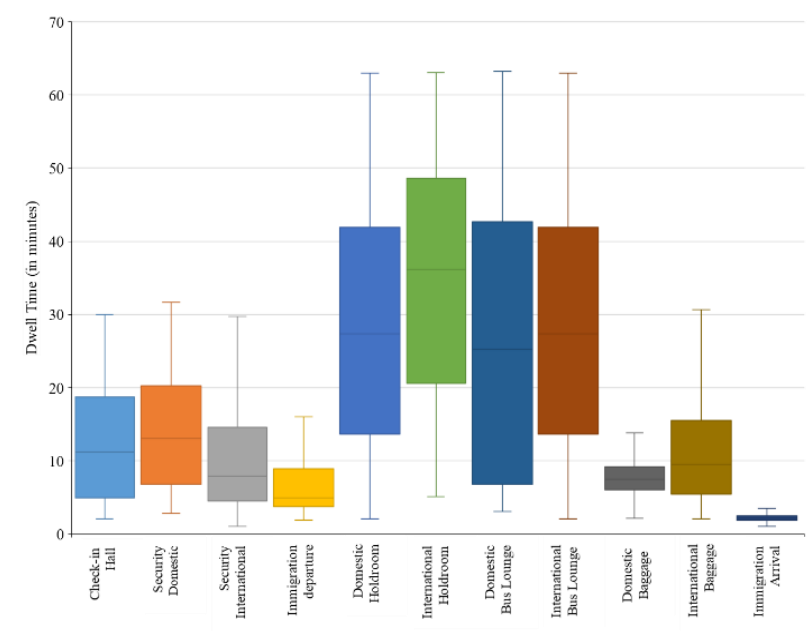

Figure 8 : Dwell time probability distribution
Energy simulation is performed with occupancy schedules generated using ABM simulation. The characteristics of heat gains in the terminal building is analysed annually and for typical summer day. Annual heat gains by envelope and infiltration for the whole terminal building are $2800 \mathrm{GJ}$ and $3000 \mathrm{GJ}$ respectively. Annual internal heat gains from the lighting is $6100 \mathrm{GJ}$ while occupant contributes around 2400 GJ. The results show a significant contribution of occupant on total internal heat gains in the terminal building.

Figure 9 shows the characteristics of occupant heat gains. The peak internal heat gain during a day is obtained at evening time with a total heating rate of $130 \mathrm{~kW}$.

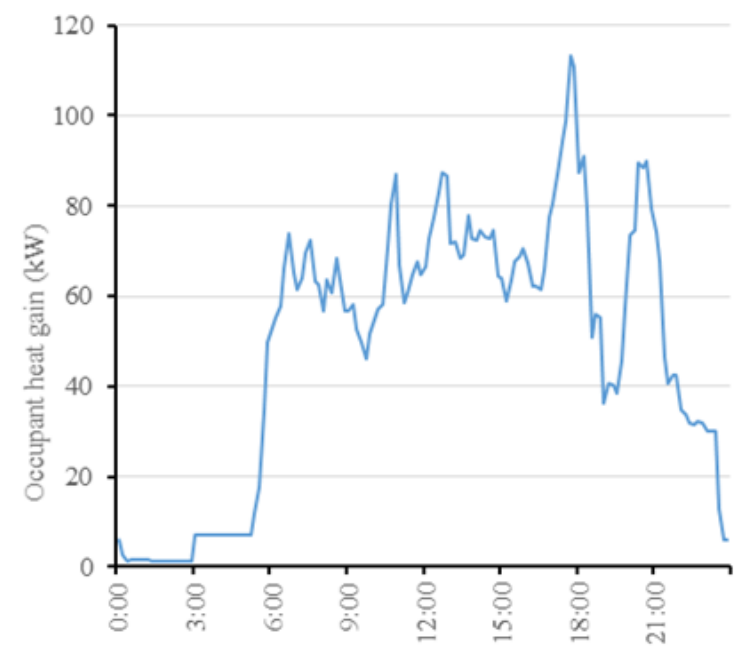

Figure 9 : Characteristic of occupant heat gains on a weekday

Figure 10 shows the result of the sub-hourly cooling load predicted with the simulated occupancy profile compared to those by the standard flight schedule profile for a typical summer weekday. In the case of flight schedule profile, peak load of $311 \mathrm{~kW}$ is obtained at 2 p.m. While in case of simulated occupancy profile, peak load of 269 $\mathrm{kW}$ is obtained at 12:30 p.m.

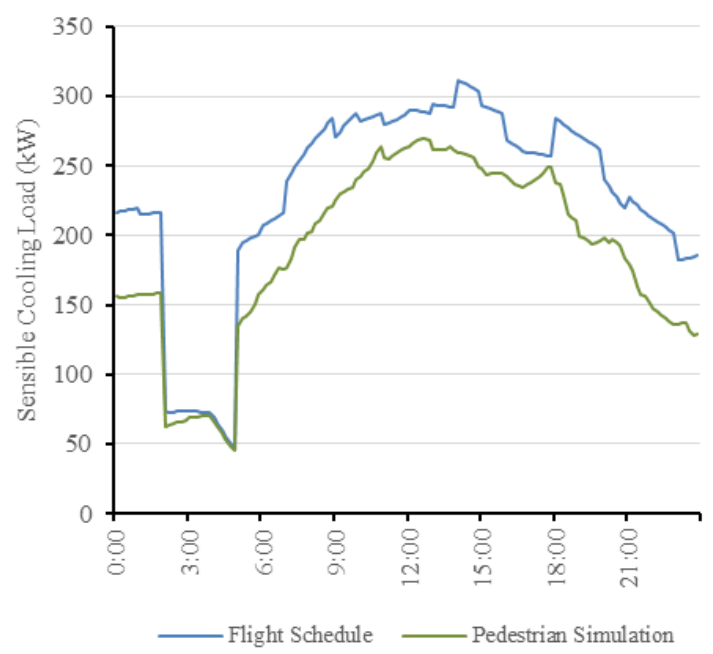

Figure 10 : Characteristics of sensible cooling load at Check-in hall in a typical summer weekday 
Figure 11 shows the variation in cooling load profile for the check-in counter simulated with different occupancy profiles i.e. flight schedules and simulated occupancy profile. Peak cooling load of $67 \mathrm{~kW}$ is obtained for both the occupancy profile.

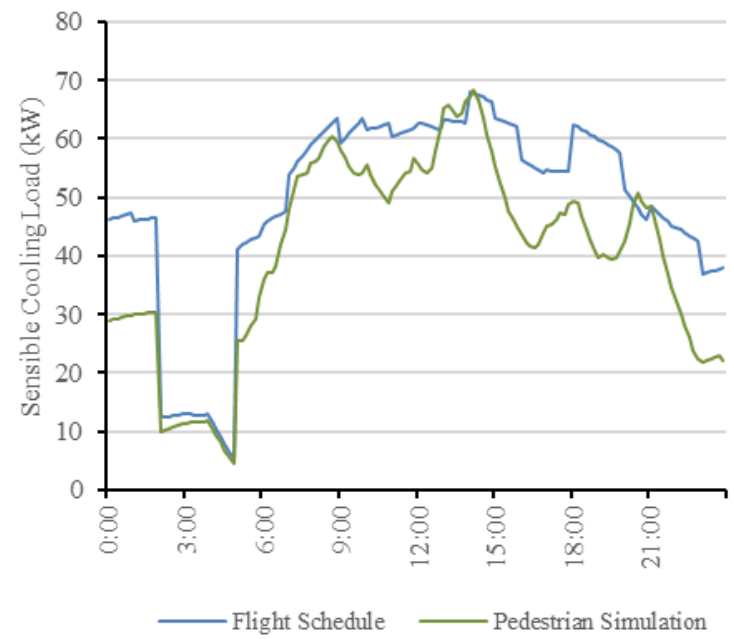

Figure 11 : Characteristics of sensible cooling load at Check-in hall in a typical summer weekday

\section{Impact of passenger density on cooling load}

The regression analysis of passenger density and their corresponding cooling load for different zones is conducted to understand the impact of passenger density on cooling load. The result shows highest correlation $\left(\mathrm{R}^{2}=0.82\right)$ obtained at the domestic security zone while least correlation of $\left(\mathrm{R}^{2}=0.18\right)$ is obtained for the immigration zone. The results indicate that impact of occupant density on cooling load is more predominant in domestic security counter. Further analysis of cooling load with the dwell time suggests that impact of occupant density on cooling load is dominant in the zone where dwell time of the passenger is more.

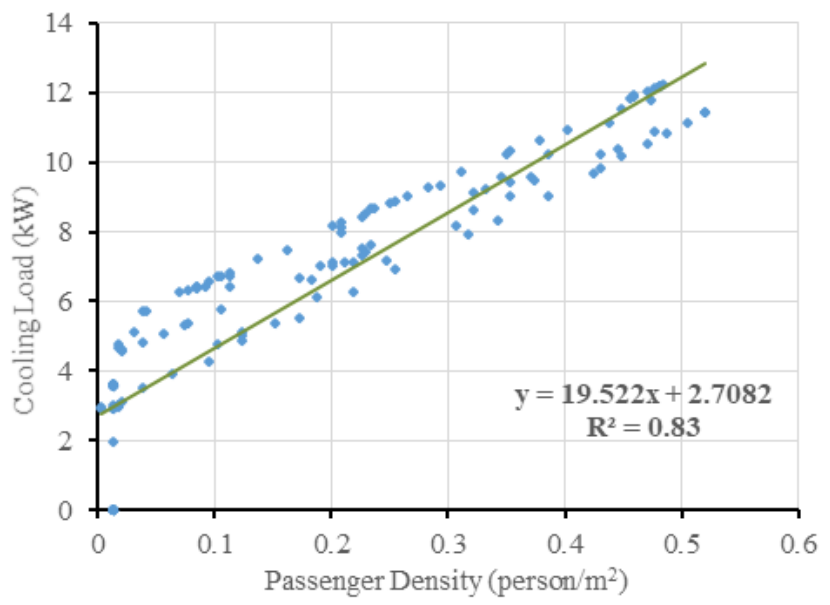

Figure 12 : Correlation of pedestrian density and cooling load at domestic security check
Table 3 : Regression analysis between pedestrian density and cooling load across zones

\begin{tabular}{|l|l|l|}
\hline Zone & Equation & $\mathbf{R}^{\mathbf{2}}$ \\
\hline Security domestic & $\mathrm{y}=19.52 \mathrm{x}+2.70$ & 0.83 \\
\hline International bus lounge & $\mathrm{y}=62.04 \mathrm{x}+8.19$ & 0.74 \\
\hline International hold-room & $\mathrm{y}=132.81 \mathrm{x}+29.51$ & 0.70 \\
\hline Domestic bus lounge & $\mathrm{y}=59.51 \mathrm{x}+10.65$ & 0.69 \\
\hline Check-in hall & $\mathrm{y}=137.76 \mathrm{x}+26.67$ & 0.59 \\
\hline Domestic hold-room & $\mathrm{y}=152.25 \mathrm{x}+38.19$ & 0.46 \\
\hline Security international & $\mathrm{y}=22.69 \mathrm{x}+3.06$ & 0.42 \\
\hline Immigration departure & $\mathrm{y}=43.51 \mathrm{x}+3.10$ & 0.32 \\
\hline Domestic baggage & $\mathrm{y}=113.17 \mathrm{x}+18.57$ & 0.29 \\
\hline International baggage & $\mathrm{y}=79.10 \mathrm{x}+17.41$ & 0.25 \\
\hline Immigration arrival & $\mathrm{y}=53.74 \mathrm{x}+4.32$ & 0.18 \\
\hline
\end{tabular}

\section{Comparison of cooling demand with different occupancy schedule}

The results indicate that there is an annual reduction of $27 \%$ of cooling demand calculated using simulated passenger schedules compared to the flight schedules while maintaining set point temperature as per ASHRAE 55 thermal comfort baseline. The results further indicate that, there is a potential for about $40 \%$ cooling demand reduction during winter and $22 \%$ during summer season. Figure 13 shows monthly comparison of cooling demand using different schedules.

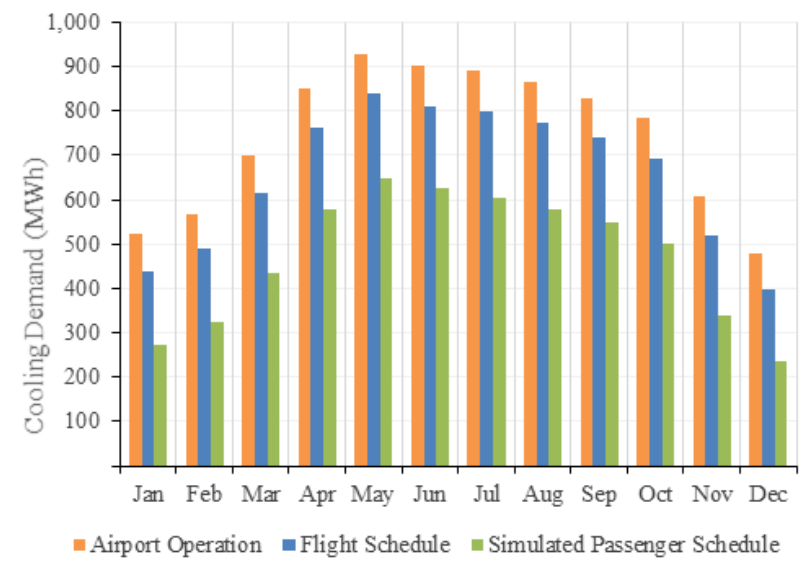

Figure 13 : Comparison of monthly cooling demand using different occupancy schedule

\section{Conclusion}

The paper describes a method of coupling an agent based occupancy model to energy simulation model in order to predict the accurate energy prediction for the terminal building application. The approach of coupling occupancy model to energy model is capable of predicting high resolution (up to 1 minute) thermal demands of a terminal building. The occupancy profile generated by the ABM is applied to energy model to derive the cooling hours. The study reveals the contribution of occupant in the total internal heat gain 
inside the terminal building. It has also been established that dynamic occupancy schedule has potential to reduce the peak demand in the terminal buildings. Further from the results of the annual cooling demand, it can be concluded that there is potential of reducing energy consumption using occupancy based controllers in the terminal buildings. The results obtained through ABM simulation are useful for developing set-point values for the HVAC and lighting controls for the different levels of occupancies among the zones.

\section{Acknowledgement}

The research described in this paper is financial supported by Department of Science and Technology, Government of India [No.:TMD/CERI/BEE/2016/07(G)]. Author would like to extend their thanks to Airport Authority of India for their valuable inputs and continuous support during the study.

\section{References}

Alba, S. O., \& Manana, M. (2016). Energy research in airports: A review. Energies, 9(5), 1-19. https://doi.org/10.3390/en9050349

B. Edwards. (2005). The Modern Airport Terminal-new Approaches to Airport Architecture (Second). Taylor \& Francis.

CASCADE Consortium. (2012). Deliverable D2.1 CASCADE Methodology for Energy Efficient Airports. Retrieved from http://www.cascadeeu.org/

Chen, Y., Hong, T., \& Luo, X. (2018). An agent-based stochastic Occupancy Simulator. Building Simulation, $\quad 11(1)$ 37-49. https://doi.org/10.1007/s12273-017-0379-7

He, M., Lee, T., Taylor, S., Firth, S. K., \& Lomas, K. (2015). COUPLING A STOCHASTIC OCCUPANCY MODEL TO ENERGYPLUS TO PREDICT HOURLY THERMAL DEMAND OF A NEIGHBOURHOOD School of Civil and Building Engineering , Loughborough University , Loughborough , UK. Building Simulation Conference, 2101-2108.

IATA. (2018). Air Passenger Forecasts Global Report.
Liu, X., Li, L., Liu, X., Zhang, T., Rong, X., Yang, L., \& Xiong, D. (2018). Field investigation on characteristics of passenger flow in a Chinese hub airport terminal. Building and Environment, 133(February), 51-61. https://doi.org/10.1016/j.buildenv.2018.02.009

Liu, X., Liu, X., Zhang, T., \& Guan, B. (2018). On-site measurement of winter indoor environment and air infiltration in an airport terminal. Indoor and Built Environment, $\quad$ O(0), 1420326X1878860. https://doi.org/10.1177/1420326X18788601

Mambo, D. A., Eftekhari, M. M., Steffen, T., \& Ahmad, M. W. (2015). Designing an occupancy flow-based controller for airport terminals. Building Services Engineering Research and Technology, 36(1), 5166. https://doi.org/10.1177/0143624414540292

Tahmasebi, F., \& Mahdavi, A. (2016). Stochastic models of occupants' presence in the context building systems control. Advances in Building Energy Research, 10(1), 1-9. https://doi.org/10.1080/17512549.2015.1050693

Verma, A., Tahlyan, D., \& Bhusari, S. (2018). Agent based simulation model for improving passenger service time at Bangalore airport. Case Studies on Transport Policy. https://doi.org/10.1016/j.cstp.2018.03.001

Virote, J., \& Neves-Silva, R. (2012). Stochastic models for building energy prediction based on occupant behavior assessment. Energy and Buildings, 53, 183-193. https://doi.org/10.1016/j.enbuild.2012.06.001

Yang, Z., Ghahramani, A., \& Becerik-Gerber, B. (2016). Building occupancy diversity and HVAC (heating, ventilation, and air conditioning) system energy efficiency. Energy, 109, 641-649. https://doi.org/10.1016/j.energy.2016.04.099

Yu, Z., Fung, B. C. M., Haghighat, F., Yoshino, H., \& Morofsky, E. (2011). A systematic procedure to study the influence of occupant behavior on building energy consumption. Energy and Buildings, 43(6), 1409-1417. https://doi.org/10.1016/j.enbuild.2011.02.002 